\title{
Mixed of Zero-inflation Method and Probability Distribution in Fitting Daily Rainfall Data
}

\author{
Kwanchai Pakoksung ${ }^{\mathrm{a} * *}$ and Masataka Takagi ${ }^{\mathrm{b}}$ \\ Kochi University of Technology, Tosayamada, Kami, Kochi, 782-0003, Japan \\ E-mail: a178011e@gs.kochi-tech.ac.jp (Corresponding author), btakagi.masataka@kochi-tech.ac.jp
}

\begin{abstract}
In hydrological processes, rainfall is one of the important components of water supply for human life. We considered how well the statistical distribution simulates rainfall intensity. We propose an asymmetric statistical probability distribution joined by zeroinflated to fit the daily continuous record of rainfall data in Thailand. The candidate statistical probabilities are General Pareto, Exponential, Beta, Gamma, Generalize extreme value, Extreme Value, Normal, Lognormal, Weibull and Rayleigh distribution, to fit the daily data from 123 rain gauges in Thailand. The statistical distributions estimated on the statistical coefficient, using the maximum likelihood estimation (MLE) method and resulted in a cumulative density function (CDF). The CDF compared to the CDF of observed data that estimated, using Kaplan-Meier algorithm. The comparisons were evaluated by Goodness of fit (GOF) in 3 null hypothesis tests (Kolmogorov-Smirnov, Anderson-Darling and Chi-Square test). The best fit distribution was identified by minimum residual $(\mathrm{R})$ index and maximum correlation (Cor) index based on difference value between the estimated and observed data. The Weibull distribution matched to the 118 rain gauges while 5 rain gauges were best fitted by the Gamma distribution.
\end{abstract}

Keywords: Thailand, rainfall statistical modelling, rainfall probability distribution, zero-inflation, goodness of fit Regional climate.

ENGINEERING JOURNAL Volume 21 Issue 2

Received 8 April 2016

Accepted 15 September 2016

Published 31 March 2017

Online at http://www.engj.org/

DOI:10.4186/ej.2017.21.2.63 


\section{Introduction}

In hydrology systems, rainfall is usually considered as the main part. Most research questions and considers the best statistical distributions to model rainfall intensity in a continuous record, while the earlier research has already analyzed only rainfall event (e.g. [1]; [2]; [3]). The distributions (Generalized-Pareto Exponential Beta, and Gamma) used to simulate hourly rainfall data from twelve stations in Peninsular Malaysia. The results suggested that the Generalized-Pareto is the best model to check from 3 Goodness-of-fit tests, Kolmogorov-Smirnov Anderson-Darling and Chi-Square [1]. The normal transform distribution, Lognormal Skew-normal and mixed Lognormal, modeled daily rainfall data. The mixed Lognormal proposed as a suitable model for the daily rainfall data for Peninsular Malaysia [2]. Leakage-law distribution identified as the best-fit distribution of monthly rainfall data in Northeast Thailand [3]. Their study collected daily rainfall data from 65 rain gauges that have a 20 -year monthly continuous record.

Several studies aimed to get the best distribution for continuous records. The statistic distribution, Kappa, Gamma, and Skewed normal, simulated data with 237 rain gauges across 49 America states. Their research report that the Kappa and Skewed normal distributions are better than the Gamma for simulation of daily data in a continuous series and only wet days [4]. Several types of mixed distribution used to find the best fit evaluated by the Akaike Information Criterion (AIC). They claimed that the mixed Lognormal outperform the other distributions (mixed Exponential Gamma, and Weibull) for continuous records in Peninsular Malaysia [5]. The continuous rainfall data, including zero data, can model to use mixed bivariate Log-normal distribution. In order to explain hydrology systems with drought or climate change effects, the zero rainfall value is one important point [6]. A zero-inflated generalized by Poisson regression distribution used to measure data [7].

Analysis of precipitation can be separated in two characteristics, occurrence and amount. The precipitation occurrence is an order of wet and dry days but the amount of precipitation models the wet days in occurring [4]. The statistical distribution such as Gamma, Exponential, Weibull, and Lognormal are applied to fit the precipitation amount that have mention on above. However, the most common distribution, the Gamma, have be implemented to fit the precipitation amount based on the wet days [5]. Several studies have researched on investigation the best distribution of precipitation amount. On hourly precipitation data, modified exponential distribution has been recommended and compared with ordinary exponential, gamma and Weibull [1]. The modified lognormal is applied to fit in the daily rainfall data to compare to ordinary lognormal [5]. However, the previous studies have been considered in the wet day that is not followed by the rainfall phenomenal [6]. It is not rain at all time. Then, its important point is to include the dry days (zero data) to explain the characteristic of drought and climate change is recommended.

The aim of our study is to decide how well the probability distributions model the daily rainfall data in the long time series scale as the continuous record. This study investigates the best-fit distribution of the continuous daily rainfall data in Thailand by using the statistical distributions joined by the zero-inflated method.

The study area characteristics described in section 2. We also give details on available Thailand rainfall data in this section. Section 3 presents our analysis of the data and our method for modeling continuous rainfall data using our stretched statistical distributions and evaluating the distributions using our hypothesis test and ranking method. The results and discussion are given in section 4, with consideration to the cumulative distribution function $(\mathrm{CDF})$, evaluation value and model ranking, while section 5 will end with conclusions.

\section{Study Area}

Thailand located in Southeast Asia and divided into 76 provinces covering an area of 513,120 square kilometers. Figure 1 shows Thailand, which is bordered by Myanmar and Laos in the north, Laos and Cambodia in the east, the Gulf of Thailand and Malaysia in the south, and the Andaman Sea and the southern extremity of Myanmar in the west. Generally, the weather is hot and humid because Thailand's location is between 5-20 degrees north latitude (the Tropical zone) $[8,9]$. Thailand's temperature normally ranges from 18 to 35 degrees Celsius and its annual rainfall ranges from 1,200 to 1,600 $\mathrm{mm}$ [10].

Rainfall in Thailand has three major sources, monsoon, the inter-tropical convergence zone and storms. Figure 1 shows the air streams that cause rainfall in Thailand. The monsoon in Thailand is seasonal, divided into two seasons, southwest monsoon and northeast monsoon [11]. The southwest monsoon, during which 
a warm air brought from the Indian Ocean, starts in May and ends in October, occurring rainfall in the country [12]. The northeast monsoon begins in October and finishes in February and brings cold and dry air from the Chinese mainland.

The inter-tropical convergence zone (ITCZ), equatorial trough or monsoon trough, which in the equatorial area is the convergence zone of two trade winds, northeasterly and southeasterly [13]. The Low atmospheric pressure area stills in the ITCZ with warm humid air rising and then cooling to produce rainfall. In May, this ITCZ arrives first in central Thailand and then moves in a northerly direction to China around June. The ITCZ moves south from China in July, dominating northern and northeastern Thailand in August with its second arrival, and later covers central and eastern Thailand in September, moving to the south Thailand in November.

Tropical cyclones and thunderstorm are the storm types in Thailand, causing a huge yearly rainfall. The tropical cyclones in Thailand come from the Pacific Ocean and the Indian Ocean [14, 15]. The South China Sea originates most of the tropical cyclones, tropical depression, tropical storm, and typhoon, which travel westward to Vietnam, Laos, Cambodia and Thailand. These cyclones cross northern and north-eastern Thailand in June to August and later move southward covering the central and eastern part from September to October, traveling across the south in November and December. In April, some cyclones originate in the Gulf of Thailand move through the east side of southern Thailand to the Andaman Sea before the southwest monsoon. In May, the beginning of rainy season, Myanmar and Thailand, the lower of the north, central and south, affected from the tropical cyclones originating in the Bay of Bengal. Thunderstorms, which are local storms, occur in summer from March to April, causing from convection and a confluence of a cold and warm moist air.

\section{Material and Methods}

The aim of this study is to develop an asymmetric statistical distribution joined by the zero-inflated method to model daily rainfall intensity and find the best-fit distribution in Thailand. The method of determining the best model of daily rainfall organized as follows. The daily rainfall dataset was collected from observed rain gauges in Thailand that control the quality using the null value to remove a given year. The details are given in section a. An empirical cumulative distribution function (ECDF) represented by the referent dataset was analyzed by using the Kaplan-Meier method. We performed to improve the asymmetric statistical distribution equation with a zero-inflated algorithm to model the continuous data. This experiment used nine statistical distributions (Generalize Pareto (GP), Exponential (Exp), Beta, Gamma, Generalize extreme value (Gev), Extreme value (Ev), Log-normal, Weibull and Rayleigh distribution) that are usually used to model the rainfall data $[4,16,17]$. Details of mathematics equation are provided in section b. All distributions were evaluated by using the goodness of fit (GOF) and the residual $(\mathrm{R})$ and correlation (Cor) coefficients were done by sorting the best fit distribution on each rain gauge.

\subsection{Datasets}

In this study, the daily rainfall data obtained from the Thai Meteorological Department Thailand. The data collected from 123 rain gauges across 73 provinces of Thailand, covering 43 years (1969-2011). Figure 2 shows the location of the collected rain gauges.

The mean record length is 37 years. The four rain gauges represented by highest annual averages are Klong Yai, Ranong, Takua Pa and Phriu Agromet over 3,000 mm/year. Because of the geographical location of these rain gauges, that located in orographic precipitation zone [18] and monsoon effect. In the middle of Thailand, covering 25 rain gauges in 3 parts, northern, northeastern and central part, have gotten the lowest annual rainfall. These rain gauges in the continental area of Southeast Asia, where the weather less affected from the monsoon [11].

The rain gauges are installed in the east coast of southern part Thailand where the rainfall gets higher annual rainfall greater than 2,000 $\mathrm{mm} /$ year because of the northeast monsoon. Also, the border of eastern and northeastern part receives a huge rainfall due to the effect of depression and typhoon from the South China Sea in the Pacific Ocean. Due to the effect of the southwest monsoon and Bengal cyclone, the west coast in the southern part obtains a huge annual precipitation represented by data of the Ranong and Takua $\mathrm{Pa}$ station. These 123 rain gauges simulated on statistical distribution to model the daily rainfall intensity. 


\subsection{Modeling Daily Rainfall Data}

Daily observation rainfall data controlled a quality, using the null values. In this section, the continuous daily data analyzed and resulted in the cumulative distribution function (CDF). These data modeled, using nine statistical distributions.

We used the Kaplan-Meier method to estimate the ECDF represented by the observed data. The Kaplan-Meier (K-M) method, proposed by E. L. Kaplan and Paul Meier [19], is normally used for survival analysis in medical science, but is also applicable for time series data [20,21] and rainfall data [22, 23]. This method summarized censored data and not assumed the value for constructing data distributions. The K-M method calculates the relative of data rank and statistical distribution based on right-censoring of the survival probability function.

Count variables, which have zero values for underlying probability distribution of counts, modeled using the zero-Inflated method. The zero-inflated method, proposed by J. Mullahy [24] and Diane Lambert [25] has applied in economics, medical, public health and hydrology [26, 27]. The method divided into two sub-models, probability distributions of zero data and positive data. The general formula of the zeroinflated is.

$$
P(Y=y)=\omega+(1-\omega) \cdot f(y)
$$

where $Y$ is the count data; $\omega$ is the zero-inflation probability, and $f(y)$ is the density of the count distribution.

The nine Candidate statistical distributions were Generalize Pareto, Exponential, Beta, Gamma, Generalize extreme value, Extreme value, Log Normal, Weibull and Rayleigh distribution. Table 1 shows the nine candidate distributions represented in a CDF form. The Generalize Pareto (GP) is the ones of continuous statistical distribution. The GP distribution, usually applies to fit tails of other distribution, is specific by two parameters, shape and scale, in this study. The Exponential (Exp) distribution is done by one parameter as the mean that have been widely used for continuous distribution. The Exp distribution is used to simulate the time lapsed during the event. The Beta distribution is also the continuous distribution, which have been defined by the interval value between 0 to 1 . This distribution has been done by two parameters for this study. The two parameters Gamma distribution has been used in this study that has a relationship with the Beta distribution. The Generalize extreme value (Gev) distribution is modified from the extreme value theory that has been developed from the Gumbel and Weibull distribution. The Gev distribution has three parameters, shape, scale and location, to use for this study. The Extreme value (Ev) have used in this study is type I (Gumbel). The Ev distribution has two parameters, shape and scale, to form in fitting the maximum number of sampling distribution. The Log Normal distribution is the continuous probability distribution that is represented by logarithm of normal distribution. In this study, the distribution have two parameter, mean and standard deviation of random variable that its standard deviation is greater than 0 . The Weibull distribution is generally contained by three parameter, shape, scale and location, but this study have used the 2-pameter Weibull. The used Weibull have with the location parameter that value is 0 . The Rayleigh distribution is specific in positive value of random variable, have one parameter as shape parameter.

We applied these nine distributions with the zero-inflection value into Eq. (1) that have shown in Table 2. The resulted distributions could be used to fit continuous daily rainfall data. In this study, these distributions had shape parameter (a), scale parameter (b), location parameter (c), and zero probability value $(w)$. The parameters were estimated by using maximum likelihood estimation method (MLE) that is occasionally used to optimize coefficient in statistical method [28]. The MLE is done by selecting a set of values of distribution parameters for underlying statistical distributions, where the selection parameter set maximizes the likelihood function [29-31]. The distribution parameters were searched to obtain results from the multi-dimension parameter sets [32].

The goodness-of-fit (GOF) test reveals how well a statistical distribution fits an observed data. The nine distributions were resulted by CDF using the parameters from MLE. The GOF test measures discrepancy between simulated and observed values [33]. This test can be applied in statistical hypothesis testing as a null hypothesis, $\mathrm{H}_{0}$ and $\mathrm{H}_{1}[16,34]$. The $\mathrm{H}_{0}$ is that the ECDF conform to the specific CDF, and the $\mathrm{H}_{1}$ is that ECDF does not conform to the specific CDF. In this study, we used 3 GOF tests (Kolmogorov-Smirnov, Anderson-Darling, and Chi-Square test) that were qualitatively controlled by significance level of $5 \%$ to screen out unsuitable distributions. 
Kolmogorov-Smirnov (K-S) test is a nonparametric test used to measure applicable continuous variable. The K-S test can be applied to evaluate the compatibility between empirical $\operatorname{CDF}(\mathrm{F}(\mathrm{x}))$ and theoretical $\mathrm{CDF}(\mathrm{G}(\mathrm{x}))$. The K-S statistic value is based on a maximum vertical difference of the both function $[35,36]$. Comparing $F(x)$ and $G(x)$, the K-S statistic is

$$
D_{K S}=\max |F(X)-G(X)|
$$

Critical values of K-S test regarding the tested statistical distribution is rejected when the P-value of tested statistic is greater than the significance level of $5 \%$ that was mentioned in the previous paragraph. The P-value of the K-S test is

$$
\begin{gathered}
Z_{K S}=D_{K S} \cdot \sqrt{n} \\
P\left(Z_{K S}\right)=2 \cdot \sum_{k=1}^{\infty}\left(-1^{K-1} \cdot \exp ^{-2 k^{2} Z_{K S}^{2}}\right)
\end{gathered}
$$

where $n$ is a sample size of the CDF, $Z_{K S}$ is the integral probability distribution.

Anderson-Darling (A-D) test, proposed by T. W. Anderson and D. A. Daring [37], is normally used for testing a specified statistical distribution. The A-D test is modified to give more weight for the tail of the K$\mathrm{S}$ test. This test statistic is defined as

$$
A^{2}=-n-\frac{1}{n} \sum_{i=1}^{n}(2 i-1) .\left[\ln F\left(X_{i}\right)+\ln \left(1-F\left(X_{n-i+1}\right)\right)\right]
$$

The A-D test is screened out an unsuitable distribution based on the significance level of $5 \%$ to mention on above. P-value of the A-D test is used to reject when it is less than the critical values at $5 \%$. The P-value of the A-D test is

$$
P\left(A^{2}\right)=\left[1+\exp ^{\left(-1+1.25 \cdot \log \left(A^{2}+4.48 \cdot A^{2}\right)\right)}\right]^{-1}
$$

Chi-Square (C-S) test, developed by Pearson in 1900s is used to compare the statistical distribution and hypothesis test [38]. The C-S test is also a nonparametric statistical test, used like the K-S test to determine whether two or more classified data are independent or dependent [39]. This test is normally used to evaluate the fit model between simulated and observed value, statistic of the test is defined as

$$
\chi^{2}=\sum_{i=1}^{k} \frac{\left(O_{i}-E_{i}\right)^{2}}{E_{i}}
$$

where $\mathrm{O}_{\mathrm{i}}$ is the observed frequency for bin $i, \mathrm{E}_{\mathrm{i}}$ is expected frequency for bin $i$ The expected frequency is estimated by

$$
E_{i}=N\left[F\left(Y_{u}\right)-F\left(Y_{l}\right)\right]
$$

where $F$ is the $\mathrm{CDF}$ of tested distribution, $Y_{u}$ is the upper limit for $i, Y_{l}$ is the lower limit for $i$, and $N$ is the sample size. A P-value of C-S test is depended on two variables, C-S statistic and degree of freedom $(d f)$, and estimated by using the Gamma function. This test can reject the tested distribution based on the critical value at $5 \%$ also on above test. The P-value of the C-S test is

$$
\begin{gathered}
d f=n-1 \\
P(C-S)=\frac{1}{\Gamma\left(\frac{\chi^{2}}{2}\right)} \int_{0}^{\frac{d f}{2}} e^{-t} t^{\frac{\chi^{2}}{2}-1} d t
\end{gathered}
$$

where $n$ is a sample size of the observation data.

The three GOF tests, which were set for a critical value at a 5\% significance level, selected some conformity distribution to model the daily rainfall as mentioned above. The CDF of the conformity distributions was generated and evaluated to find the best distribution. An evaluation index, two coefficients (residual $(R)$ and correlation $($ Cor $)$ ), which was calculated as the difference between observed 
CDF represented by ECDF and simulated CDF, was used to assess the best fit simulation distribution [16, 40]. The $R$ and Cor coefficient are defined as

$$
\begin{gathered}
R=\frac{\sum_{i=1}^{n}\left|O_{i}-E_{i}\right|}{n} \\
\operatorname{Cor}=\frac{\sum_{i=1}^{n}\left(O_{i}-\bar{O}\right) \cdot \sum_{i=1}^{n}\left(E_{i}-\bar{E}\right)}{\sqrt{\sum_{i=1}^{n}\left(O_{i}-\bar{O}\right)^{2}} \cdot \sqrt{\sum_{i=1}^{n}\left(E_{i}-\bar{E}\right)^{2}}}
\end{gathered}
$$

where $\mathrm{O}_{\mathrm{i}}$ is observed data, $\mathrm{E}_{\mathrm{i}}$ is estimated data and $n$ is a total number of sampling data.

The ranking method for finding the best fit distribution used a ranking number that represents among the nine distributions to create an order number between 1 and 9 . The order number is marked on each distribution by using the $R$ and $C o r$ coefficient. To identify the order number, the distribution contain the lowest $R$ and the highest $C o r$, is rank number 1, while the rank number 9 is the highest $R$, and lowest $C o r$. The best fit coefficient was calculated by an average of the ranking based on the $R$, and Cor coefficient. The best fit probability distribution was identified as the minimum of the best fit coefficient.

\section{Results and Discussion}

The methodology mentioned above was applied to 123 rain gauges Thailand, covered 37 years of daily data for the continuous temporal data. According to a results, the cumulative distribution function (CDF) and the probability in the different distributions have shown in the first. Analysis of the results in the middle, a goodness-of-fit test, and a ranking test result were presented. Finally, the best-fit distribution of each rain gauge was shown.

On fitting distribution result, all rain gauges data were fitted by using the nine distributions resulted in CDF. The nine simulated CDFs were compared to ECDF by $95 \%$ confidence interval of the ECDF for evaluation. Kolmogorov-Smirnov (K-S), Anderson-Darling (A-D) and Chi-Square (C-S) test was used and analyzed on the nine distributions in each rain gauge to screen an incompatible distribution base on the level of significance. The incompatible distribution was identified by P-value on the significance level at 0.05. Table 3 shows the conformable distribution for selecting this compatible distribution based on the hypothesis test, when the two-thirds of 3 hypothesis tests were acceptable, the tested distribution was selected. On the other hand, unselected distribution was identified in the two-thirds of 3 hypothesis tests are rejected. The best-fit distribution was based on residual $(R)$ and correlation $(C o r)$ coefficient between simulation and observation CDF. For the best model, the minimum value of the $R$ and the maximum value of the Cor were selected. Summary ranking could be calculated by the average of both coefficients, was used to identify the best-fit distribution. Weibull distribution among the eight distributions was the best model on the acid area. The 123 rain gauges have gotten the results with the processes as above.

The best probability distribution of all rain gauges (Fig. 3) was plotted by using its coordinate based on latitude and longitude. The rain gauge coordinate was used to distribute presented on the spatial map by using the Kriging algorithm [41]. The map was used to show the boundary of fitting distribution. The poorly fitted parameters of the spherical semi-variogram model on the spatial mapping were the nugget variance $\left(C_{0}\right)$ is 0.01 , the partial sill $(C)$ is 0.04 and the range $(a)$ is 5.0 degree, are used to analyze. Weibull distribution conforms to 118 stations while 5 rain gauge stations fit to the Gamma distribution. Most of the stations, which are located in the continental area, fitted to the Weibull distribution. The 5 rain gauges accepted with the Gamma distribution are the highest annual rainfall zone that has been influenced by the monsoon and typhoon. Ranong station fitted to the Gamma that is located at the foot of the mountain and affected by the southwest monsoon and the Bengol Cyclone. Also, Phriu Agr and Khlong Yai same as the Ranong station where the location have influenced from the northeast monsoon and typhoon. While the both Nakhon Phanom station located far from the mountain are influenced by the typhoon to get the high annual rainfall and fitted to the Gamma distribution.

The study results can be compared to the several researches that the comparison is only relative as fitted distribution name, while the other components are different such as temporal scale, rainfall event, and location domain. Based on the location in the Phrae province, The 9 rain gauges of the study was fitted by the Weibull distribution, while the previous study these 9 rain gauges was fitted by the Extreme value 
distribution [42]. Also, by the contrast, the fitted distribution on the previous study on the north-eastern part was presented by the Leakage distribution that was different to this study [3]. This study results showed the Weibull distribution that fitted to the rain gauge data on the north-eastern part. The results on the southern part was indirectly compared to neighbor area as Malesia that the fitted distribution of the neighbor country was Lognormal [5]. The fitted distribution of this study was the Weibull that contrasted to the previous study.

Generally, the modeling distribution results have gotten an effect from the difference of elevation and location of rain gauges, including monsoon and typhoon. Also, the results will be influenced by terrain and climate change.

\section{Concluding Remarks}

Our goal was to consider compatible statistical distribution for daily rainfall data to simulate rainfall intensity. This research indicates that the continue data can be fitted by using probability distribution with a zero-inflated approach. The tested distributions are General Pareto, Exponential, Beta, Gamma, Generalize extreme value, Extreme value, Log-normal, Weibull, and Rayleigh distributions.

We found that a statistical distribution with zero-inflated on Weibull distribution was the most fitted distribution of daily rainfall intensity in Thailand with the goodness of fit score between observed and simulated value based on hypothesis test, maximum correlation (Cor) and minimum residual (R). In the second favorite distribution, the rain gauge stations were fitted by Gamma distribution, located in huge and orographic precipitation zone. In summary rainfall in Thailand, the rain gauge data are greatly influenced by their elevation, terrain and climate change to provide uncertainty on the rainfall distribution.

The scientific approach sufficiently established that the analytical methodology devised and test in this study may be utilized for the identification of the best fit statistical probability distribution of weather parameters. However, our statistical distributions can be used available to the scientific community through the hydrology modeling for use in the rainfall prediction application to water resources management and Meteorology research.

\section{Acknowledgements}

The study cannot be conducted without the data provided from various agencies, e.g., Royal Irrigation Department, Thai Meteorological Department and Land Development Department etc. Kochi University of Technology has been supported in part with Takagi laboratory.

\section{References}

[1] S. Dan'azami, S. Shamsudin, and A. Aris, "Modeling of rainfall intensity using hourly data," American Journal of Environmental Sciences, vol. 6, pp. 238-243, 2010.

[2] J. Suhaila and A. A. Jemain, "Fitting daily rainfall amount in Malaysia using the normal transform distribution," Journal of Applied Sciences, vol. 7, pp. 1880-1886, 2007.

[3] H.N. Phien, A. Arbhabhirama, and A. Sunchindah, "Rainfall distribution in northeastern Thailand," Hydrological Sciences-Bulletin, vol. 25, pp. 167-182, 1980.

[4] L. S. Hanson and R. Vogel, "The probability distribution of daily rainfall in the United States," in World Environmental and Water Resources Congress 2008, Honolulu, Hawaii, USA, May 12-16, 2008, pp. 112.

[5] J. Suhaila,, K. Ching-Yee,, T. Fadhilah,, F. Hui-Mean, "Introduction the mixed distribution in fitting rainfall data," Open Journal of Modern bydrology, vol. 1, pp. 11-22, 2011.

[6] E. Ha and C. Yoo, "Use of mixed bivariate distributions for deriving inter-station correlation coefficients of rain rate," Hydrological Processes, vol. 21, pp. 3078-3086, 2007.

[7] F. Famoye and K. P. Singh, "Zero-inflated generalized Poisson regression model with an application to domestic violence data," Journal of Data Science, vol. 4, pp. 117-130, 2006.

[8] C. Thongkamsamut, "The building technological solution for hot humid climate modification in architecture," International Journal of Renewable Energy, vol. 5, pp. 11-25, 2010.

[9] Y. Zhao, C. Wang, and S. Wang, "Impacts of present and future climate variability on agriculture and forestry in the humid and sub-humid tropics," Climate Change, vol. 70, pp. 73-116, 2005. 
[10] Climatological Centre, "Weather summary in Thailand report," Meteorological Development Bureau Meteorological Department, BKK, Thailand, 2012.

[11] Y. Y. Loo, L. Billa, and A. Singh, "Effect of climate change on seasonal monsoon in Asia and its impact on the variability of monsoon rainfall in Southeast Asia," International Journal of Renewable Energy, vol. 10, pp. 1-7, 2014.

[12] A. Limsakul, S. Limjirakan, and B. Suttamanuswong, "Asian summer monsoon and its associated rainfall variability in Thailand," Environment Asia, vol. 3, pp. 79-89, 2010.

[13] T. Schneider, T. Bischoff, and G. H. Hang, "Migrations and dynamics of the intertropical convergence zone," Nature, vol. 513, pp. 45-53, 2014.

[14] Climatological Centre, "Tropical cyclones in Thailand historical data 1951-2010 report," Meteorological Development Bureau Meteorological Department, BKK, Thailand, 2011.

[15] P. A. Harr and J. C. L. Chan, "Monsoon impact tropical cyclone variability," TMRP Report No. 70", World Meteorological Organization, Hangzhou, China, 2005.

[16] M. A. Sharma and J. B. Singh, "Use of probability distribution in rainfall analysis," New York Science Journal, vol. 3, pp. 40-49, 2010.

[17] S. Dan'azumi, S. Shamsudin, and A. A. Rahman, "Probability distribution of rainfall depth at hourly time-scale," International Journal of Environment, Earth Science and Engineering, vol. 4, pp. 1-5, 2010.

[18] Q. Jiang, "Moist dynamics and orographic precipitation," Tellus, vol. 55A, pp. 301-316, 2003.

[19] E. L. Kaplan and P. Meier, "Nonparametric estimation from incomplete observations," Journal of the American Statistical Association, vol. 53, pp. 457-481, 1958.

[20] A. Picado, C. L. Lopes, R. Mendes, N. Vas, and J. M. Dias, "Storm surge impact in the hydrodynamics of tidal lagoon: the case of Ria de Aveiro," Journal of Coastal Research, vol. 65, no. sp1, pp. 796-801, 2013.

[21] Z. Cai and G.G. Roussas, "Kaplan-Meier estimator under association," Journal of Multivariate Analysis, vol. 67, pp. 318-348, 1998.

[22] A. Atencia, L. Mediero, M.C. Llasat, and L. Garrote, "Effect of radar rainfall time resolution on the predictive capability of a distributed hydrologic model," Hydrology and Earth System Sciences, vol. 15, pp. 3809-3827, 2011.

[23] F. Oriani, J. Straubhaar, P. Renard, and G. Mariethoz, "Simulation of rainfall time series from different climatic regions using the direct sampling technique," Hydrology and Earth System Sciences, vol. 18, pp. 3015-3031, 2014.

[24] J. Mullahy, "Specification and test of some modified count data models," Journal of Econometrics, vol. 33, pp. 341-365, 1986.

[25] D. Lambert, "Zero-inflated poisson regression, with an application to defects in manufacturing," Technometrics, vol. 34, pp. 1-14, 1992.

[26] J. Ngatchou-Wandji and P. Chritophe, "On the zero-inflated count models with application to modelling annual trends in incidences of some occupational allergic diseases in France," Journal of Data Science, vol. 9, pp. 639-659, 2011.

[27] J. Suhaila, K. Ching-Yee, F. Yusof, and F. Hui-Mean, "Effect of zero measurements in rainfall data," Journal Teknologi, vol. 63, pp. 35-39, 2013.

[28] I. J. Myung, "Tutorial on maximum likelihood estimation," Journal of Mathematical Psychology, vol. 47, pp. 90-100, 2003.

[29] S. Geman and C. Hwang, "Nonparametric maximum likelihood estimation by the method of sieves," The Annals of Statistics, vol. 10, pp. 401-414, 1982.

[30] C. Uhler, "Geometry of maximum likelihood estimation in Gaussian graphical models," The Annals of Statistics, vol. 40, pp. 238-261, 2012.

[31] K Huang, S. T. Guo, M. R. Shattuck, S. T. Chen, X. G. Qi, P. Zhang, and B. G. Li, "A maximumlikelihood estimation of pairwise relatedness for autopolyploid," Heredity, vol. 114, pp. 133-142, 2015.

[32] S. E. Fienberg and A. Rinaldo, "Maximum likelihood estimation in log-linear models," The Annals of Statistics, vol. 40, pp. 996-1023, 2012.

[33] A. Maydeu-Olivares, "Goodness-of-fit assessment of item response theory models," Measurement: Interdisciplinary Research and Perspectives, vol. 11, pp. 71-101, 2013.

[34] R. D. Morey and E.J. Wagenmakers, "Simple relation between Bayesian order-restricted and point-null hypothesis tests," Statistics and Probability Letters, vol. 92, pp. 121-124, 2014.

[35] J. Frank and J. Massey, "The Kolmogorov-Smirnov test for goodness of fit," Journal of the American Statistical Association, vol. 46, pp. 68-78, 1951. 
[36] A. Justel, D. Pefia, and R. Zamar, "A multivariate Kolmogorov-Smirnov test of goodness of fit," Statistics and Probability Letters, vol. 35, pp. 251-259, 1997.

[37] T. W. Anderson and D. A. Darling, "A test of goodness of fit," Journal of the American Statistical Association, vol. 49, pp. 765-769, 1954.

[38] R. L. Plackett, "Karl Pearson and the chi-squared test," International Statistical Review, vol. 51, pp. 59-72, 1983.

[39] S. D. Bolboaca, L. Jantschi, A. F. Sestras, R. E. Sestras, and D. C. Pamfil, "Pearson-Fisher chi-square statistic revisited," Information, vol. 2, pp. 528-545, 2011.

[40] D. J. Prosser, J. Wu, E. C. Ellis, F. Gale, T. P. V. Boeckel, W. Wint, T. Robinson, X. Xiao, M. Gilbert, "Modelling the distribution of chickens, ducks, and geese in China," Agriculture, Ecosystems and Environment, vol. 141, pp. 381-389, 2011.

[41] S. Ly, C. Charles, and A. Degre, "Geostatistical interporation of daily rainfall at catchment scale: the use of several variogram models in the Ourthe and Ambleve catchments, Belgium," Hydrol. Earth Syst. Sci., vol. 15, pp. 2259-2274, 2011.

[42] T. Tingsanchili and F. Karim, "Flood-hazard assessment and risk-based zoning of a tropical flood plain: case study of the Yom River, Thailand," Hydrological Sciences Journal, vol. 55, pp. 154-161, 2010. 


\section{Appendix I: List of Tables}

Table 1. Description of asymmetric statistical distribution functions.

\begin{tabular}{|c|c|c|}
\hline Distribution & $\mathrm{CDF}$ & Parameter \\
\hline GP $(2 \mathrm{P})$ & $F(x \mid a, b)=1-e^{\left(-\frac{x-a}{b}\right)}$ & $\begin{array}{l}a=\text { shape parameter } \\
b=\text { scale parameter }\end{array}$ \\
\hline Exp & $F(x \mid a)=1-e^{-a x}$ & $a=$ mean \\
\hline & $F(x \mid a, b)=I_{x}(a, b)$ & $\left.a^{a}\right\}=$ shape parameter \\
\hline Beta & $I_{x}(a, b)=\frac{\int_{0}^{x} t^{a-1} \cdot(1-t)^{b-1} d t}{\mathrm{~B}(a, b)}$ & $\begin{array}{l}B=\text { Beta function } \\
I=\text { Indicator function }\end{array}$ \\
\hline Gamma (2P) & $F(x \mid a, b)=\frac{b^{-a} \cdot x^{a-1} \cdot e^{\frac{-x}{b}}}{\Gamma(a)}$ & $\begin{array}{l}a=\text { shape parameter } \\
b=\text { scale parameter } \\
\Gamma=\text { Gamma function }\end{array}$ \\
\hline Gev & $F(x \mid a, b, c)=e^{\left\{-\left[1+c\left(\frac{x-a}{b}\right)\right]^{\frac{-1}{c}}\right\}}$ & $\begin{array}{l}a=\text { shape parameter } \\
b=\text { scale parameter } \\
c=\text { location parameter }\end{array}$ \\
\hline Ev (Type I) & $F(x \mid a, b)=1-e^{-e^{\left(\frac{x-a}{b}\right)}}$ & $\begin{array}{l}a=\text { shape parameter } \\
b=\text { scale parameter }\end{array}$ \\
\hline Log Normal & $F(x \mid a, b)=\Phi\left(\frac{\log (x)-a}{b}\right)$ & $\begin{array}{l}a=\text { mean } \\
b=\text { standard Deviation } \\
(b>0)\end{array}$ \\
\hline Weibull (2P) & $F(x \mid a, b)=1-e^{-\left(\frac{x}{b}\right)^{a}}$ & $\begin{array}{l}a=\text { shape parameter } \\
b=\text { scale parameter }\end{array}$ \\
\hline Rayleigh & $F(x \mid a)=1-e^{\frac{-x^{2}}{2 a^{2}}}$ & $a=$ shape parameter \\
\hline
\end{tabular}


Table 2. Mixed distribution functions.

\begin{tabular}{|c|c|}
\hline Distribution & ZI-CDF \\
\hline GP (2P) & $F(x)=1-\omega+\omega \cdot e^{\left(-\frac{x-a}{b}\right)}$ \\
\hline Exp & $F(x)=1-\omega+\omega \cdot e^{-a x}$ \\
\hline Beta & $F(x)=\omega+I_{x}(a, b)-\omega \cdot I_{x}(a, b)$ \\
\hline Gamma (2P) & $F(x)=\omega+\frac{b^{-a} \cdot x^{a-1} \cdot e^{\frac{-x}{b}}}{\Gamma(a)}-\omega \cdot \frac{b^{-a} \cdot x^{a-1} \cdot e^{\frac{-x}{b}}}{\Gamma(a)}$ \\
\hline Gev & $F(x)=\omega+(1-\omega) \cdot e^{\left\{-\left[1+c\left(\frac{x-a}{b}\right)\right]^{\frac{-1}{c}}\right\}}$ \\
\hline $\mathrm{Ev}(2 \mathrm{P})$ & $F(x)=1-\omega+\omega \cdot e^{-e^{\left(\frac{x-a}{b}\right)}}$ \\
\hline Log Normal & $F(x)=\omega+(1-\omega) \cdot \Phi\left(\frac{\log (x)-a}{b}\right)$ \\
\hline Weibull (2P) & $F(x)=1-\omega+\omega \cdot e^{-\left(\frac{x}{b}\right)^{a}}$ \\
\hline Rayleigh & $F(x)=1-\omega+\omega \cdot e^{\frac{-x^{2}}{2 a^{2}}}$ \\
\hline & $\begin{array}{l}\quad \text { where } \\
a=\text { shape parameter } \\
b=\text { scale parameter } \\
\mathrm{c}=\text { location parameter } \\
\omega=\text { zero }- \text { inflation probability }\end{array}$ \\
\hline
\end{tabular}


Table 3. The fit parameter of best fit distribution in each rain gauge.

\begin{tabular}{|c|c|c|c|c|c|c|c|}
\hline No & station & code & $\begin{array}{c}\text { Mean, } \\
\text { mm }\end{array}$ & Fit dist. & Inflated & shape & scale \\
\hline 1 & Mae Hong Son* & 300201 & 1304.6 & Weibull & 0.620 & 0.741 & 7.785 \\
\hline 2 & Mae Sariang* & 300202 & 1183.4 & Weibull & 0.610 & 0.783 & 7.173 \\
\hline 3 & Chiang Rai* & 303201 & 1744.8 & Weibull & 0.628 & 0.741 & 10.653 \\
\hline 4 & Chiang Rai Agromet & 303301 & 1696.5 & Weibull & 0.626 & 0.732 & 10.199 \\
\hline 5 & Phayao* & 310201 & 1219.4 & Weibull & 0.617 & 0.729 & 7.094 \\
\hline 6 & Mae Jo & 327301 & 1135.2 & Weibull & 0.668 & 0.714 & 7.435 \\
\hline 7 & Chiang Mai & 327501 & 1174.4 & Weibull & 0.680 & 0.719 & 8.070 \\
\hline 8 & Lampang* & 328201 & 1091.5 & Weibull & 0.690 & 0.709 & 7.630 \\
\hline 9 & Lampang Agromet & 328301 & 1161.4 & Weibull & 0.633 & 0.704 & 6.825 \\
\hline 10 & Lamphun* & 329201 & 1085.3 & Weibull & 0.663 & 0.679 & 6.715 \\
\hline 11 & Phrae* & 330201 & 1130.2 & Weibull & 0.687 & 0.688 & 7.576 \\
\hline 12 & Nan* & 331201 & 1270.6 & Weibull & 0.671 & 0.714 & 8.425 \\
\hline 13 & Nan Agromet & 331301 & 1345.5 & Weibull & 0.657 & 0.701 & 8.450 \\
\hline 14 & Tha Wang Pha* & 331401 & 1437.2 & Weibull & 0.650 & 0.720 & 9.033 \\
\hline 15 & Thung Chang & 331402 & 1484.4 & Weibull & 0.598 & 0.716 & 8.077 \\
\hline 16 & Uttaradit* & 351201 & 1438.5 & Weibull & 0.681 & 0.675 & 9.329 \\
\hline 17 & Nong Khai* & 352201 & 1630.7 & Weibull & 0.652 & 0.693 & 9.987 \\
\hline 18 & Loei* & 353201 & 1270.9 & Weibull & 0.653 & 0.676 & 7.570 \\
\hline 19 & Loei Agromet & 353301 & 1255.2 & Weibull & 0.678 & 0.722 & 8.599 \\
\hline 20 & Udon Thani* & 354201 & 1446.4 & Weibull & 0.669 & 0.689 & 9.198 \\
\hline 21 & Sakon Nakhon* & 356201 & 1633.8 & Weibull & 0.646 & 0.692 & 9.772 \\
\hline 22 & Sakon Nakhon Agromet & 356301 & 1566.5 & Weibull & 0.664 & 0.717 & 10.234 \\
\hline 23 & Nakhon Phanom* & 357201 & 2333.4 & Gamma & 0.621 & 0.590 & 28.571 \\
\hline 24 & Nakhon Phanom Agromet & 357301 & 2057.8 & Gamma & 0.651 & 0.635 & 25.412 \\
\hline 25 & Nongbualumphu & 360201 & 1384.3 & Weibull & 0.503 & 0.731 & 6.212 \\
\hline 26 & Sukhothai & 373201 & 1255.6 & Weibull & 0.573 & 0.574 & 4.871 \\
\hline 27 & Si Samrong Agromet & 373301 & 1234.1 & Weibull & 0.701 & 0.677 & 8.590 \\
\hline 28 & Tak* & 376201 & 1074.0 & Weibull & 0.713 & 0.689 & 7.870 \\
\hline 29 & Mae Sot* & 376202 & 1470.0 & Weibull & 0.614 & 0.754 & 8.742 \\
\hline 30 & Bhumibol Dam* & 376203 & 1077.8 & Weibull & 0.703 & 0.660 & 7.251 \\
\hline 31 & Doi Muser Agromet Stn. & 376301 & 1346.2 & Weibull & 0.526 & 0.727 & 6.271 \\
\hline 32 & Umphang* & 376401 & 1448.9 & Weibull & 0.550 & 0.802 & 7.749 \\
\hline 33 & Phitsanulok* & 378201 & 1359.7 & Weibull & 0.677 & 0.676 & 8.754 \\
\hline 34 & Phetchabun* & 379201 & 1124.9 & Weibull & 0.674 & 0.720 & 7.585 \\
\hline 35 & Lom Sak* & 379401 & 1045.0 & Weibull & 0.677 & 0.708 & 6.966 \\
\hline 36 & Wichian Buri* & 379402 & 1229.5 & Weibull & 0.693 & 0.731 & 8.917 \\
\hline 37 & Kamphaeng Phet* & 380201 & 1286.8 & Weibull & 0.611 & 0.718 & 7.219 \\
\hline 38 & Khon Kaen* & 381201 & 1239.5 & Weibull & 0.707 & 0.682 & 8.813 \\
\hline
\end{tabular}


Table 3. The fit parameter of best fit distribution in each rain gauge (continues).

\begin{tabular}{|c|c|c|c|c|c|c|c|}
\hline No & station & code & $\begin{array}{c}\text { Mean, } \\
\text { mm }\end{array}$ & Fit dist. & Inflated & shape & scale \\
\hline 39 & Tha Phra Agromet & 381301 & 1187.2 & Weibull & 0.722 & 0.689 & 8.967 \\
\hline 40 & Mukdahan* & 383201 & 1512.0 & Weibull & 0.682 & 0.691 & 10.073 \\
\hline 41 & Pichit Agromet & 386301 & 1284.1 & Weibull & 0.592 & 0.679 & 6.537 \\
\hline 42 & Kosum Phisai* & 387401 & 1249.7 & Weibull & 0.717 & 0.707 & 9.560 \\
\hline 43 & Kamalasai & 388401 & 1350.1 & Weibull & 0.578 & 0.664 & 6.436 \\
\hline 44 & Nakhon Sawan* & 400201 & 1141.2 & Weibull & 0.701 & 0.672 & 7.855 \\
\hline 45 & Tak Fa Agromet & 400301 & 1199.5 & Weibull & 0.702 & 0.696 & 8.565 \\
\hline 46 & Chai Nat* & 402301 & 1060.6 & Weibull & 0.724 & 0.711 & 8.334 \\
\hline 47 & Chaiyaphum* & 403201 & 1146.8 & Weibull & 0.721 & 0.685 & 8.655 \\
\hline 48 & Roi Et* & 405201 & 1362.1 & Weibull & 0.699 & 0.694 & 9.652 \\
\hline 49 & Roi Et Agromet & 405301 & 1348.5 & Weibull & 0.686 & 0.652 & 8.598 \\
\hline 50 & Ubon Ratchathani Agromet & 407301 & 1611.9 & Weibull & 0.671 & 0.704 & 10.629 \\
\hline 51 & Ubon Ratchathani* & 407501 & 1604.9 & Weibull & 0.673 & 0.704 & 10.605 \\
\hline 52 & Si Sa Ket Agromet & 409301 & 1458.7 & Weibull & 0.646 & 0.711 & 8.968 \\
\hline 53 & Ayuttaya Agromet & 415301 & 1156.7 & Weibull & 0.547 & 0.733 & 5.655 \\
\hline 54 & Pathumthani Agromet & 419301 & 1251.5 & Weibull & 0.530 & 0.667 & 5.365 \\
\hline 55 & Chacherngsao Agromet & 423301 & 1419.2 & Weibull & 0.541 & 0.776 & 7.250 \\
\hline 56 & Ratchaburi & 424301 & 1158.6 & Weibull & 0.557 & 0.736 & 5.813 \\
\hline 57 & Suphan Buri* & 425201 & 1040.6 & Weibull & 0.721 & 0.674 & 7.664 \\
\hline 58 & U Thong Agromet & 425301 & 1032.9 & Weibull & 0.726 & 0.685 & 7.848 \\
\hline 59 & Lop Buri* & 426201 & 1136.8 & Weibull & 0.722 & 0.712 & 8.920 \\
\hline 60 & Bua Chum* & 426401 & 1106.7 & Weibull & 0.710 & 0.698 & 8.117 \\
\hline 61 & Pilot Station* & 429201 & 1070.8 & Weibull & 0.664 & 0.701 & 6.804 \\
\hline 62 & Suwanabhum Airport & 429601 & 1410.0 & Weibull & 0.453 & 0.664 & 5.200 \\
\hline 63 & Prachin Buri* & 430201 & 1878.3 & Weibull & 0.631 & 0.724 & 11.314 \\
\hline 64 & Kabin Buri* & 430401 & 1629.9 & Weibull & 0.631 & 0.741 & 10.041 \\
\hline 65 & Nakhon Ratchasima* & 431201 & 1062.2 & Weibull & 0.700 & 0.663 & 7.145 \\
\hline 66 & Pak Chong Agromet & 431301 & 1132.4 & Weibull & 0.666 & 0.699 & 7.228 \\
\hline 67 & Chok Chai* & 431401 & 1098.9 & Weibull & 0.689 & 0.681 & 7.338 \\
\hline 68 & Surin* & 432201 & 1398.2 & Weibull & 0.680 & 0.700 & 9.390 \\
\hline 69 & Surin Agromet & 432301 & 1429.0 & Weibull & 0.687 & 0.706 & 9.844 \\
\hline 70 & Tha Tum* & 432401 & 1384.0 & Weibull & 0.694 & 0.690 & 9.595 \\
\hline 71 & Burirum* & 436201 & 1371.8 & Weibull & 0.539 & 0.692 & 6.303 \\
\hline 72 & Nang Rong* & 436401 & 1208.5 & Weibull & 0.679 & 0.706 & 8.098 \\
\hline 73 & Aranyaprathet* & 440201 & 1373.3 & Weibull & 0.644 & 0.735 & 8.690 \\
\hline 74 & Sa Kaew & 440401 & 1531.3 & Weibull & 0.516 & 0.751 & 7.247 \\
\hline 75 & Kanchanaburi* & 450201 & 1078.9 & Weibull & 0.698 & 0.673 & 7.274 \\
\hline 76 & Thong Pha Phum* & 450401 & 1735.0 & Weibull & 0.585 & 0.830 & 10.306 \\
\hline
\end{tabular}


Table 3. The fit parameter of best fit distribution in each rain gauge (continues).

\begin{tabular}{|c|c|c|c|c|c|c|c|}
\hline No & station & code & $\begin{array}{l}\text { Mean, } \\
\mathrm{mm}\end{array}$ & Fit dist. & Inflated & shape & scale \\
\hline 77 & Kamphaeng Saen Agromet & 451301 & 1053.5 & Weibull & 0.694 & 0.695 & 7.294 \\
\hline 78 & Bangkok Metropolis* & 455201 & 1589.4 & Weibull & 0.647 & 0.685 & 9.485 \\
\hline 79 & Klong Toey* & 455203 & 1569.5 & Weibull & 0.610 & 0.636 & 7.820 \\
\hline 80 & Bang $\mathrm{Na}^{*}$ & 455301 & 1516.4 & Weibull & 0.663 & 0.692 & 9.518 \\
\hline 81 & Bang Khen* & 455302 & 1444.6 & Weibull & 0.592 & 0.665 & 7.208 \\
\hline 82 & Donmuang & 455601 & 1330.3 & Weibull & 0.691 & 0.720 & 9.519 \\
\hline 83 & Chon Buri* & 459201 & 1294.7 & Weibull & 0.674 & 0.689 & 8.403 \\
\hline 84 & Ko Sichang* & 459202 & 1217.1 & Weibull & 0.718 & 0.689 & 9.096 \\
\hline 85 & Phatthaya* & 459203 & 1172.5 & Weibull & 0.640 & 0.680 & 6.732 \\
\hline 86 & Sattahip* & 459204 & 1308.9 & Weibull & 0.700 & 0.707 & 9.371 \\
\hline 87 & Lam Chabang* & 459205 & 1207.8 & Weibull & 0.584 & 0.641 & 5.588 \\
\hline 88 & Phetchaburi* & 465201 & 1046.1 & Weibull & 0.642 & 0.687 & 6.021 \\
\hline 89 & Rayong* & 478201 & 1418.2 & Weibull & 0.615 & 0.673 & 7.519 \\
\hline 90 & Huai Pong Agromet & 478301 & 1420.3 & Weibull & 0.667 & 0.698 & 9.129 \\
\hline 91 & Chanthaburi* & 480201 & 2932.5 & Weibull & 0.542 & 0.718 & 14.128 \\
\hline 92 & Phriu Agromet & 480301 & 3199.0 & Gamma & 0.521 & 0.604 & 30.231 \\
\hline 93 & Prachuap Khiri Khan* & 500201 & 1140.0 & Weibull & 0.664 & 0.642 & 6.459 \\
\hline 94 & Hua Hin* & 500202 & 984.6 & Weibull & 0.700 & 0.631 & 6.060 \\
\hline 95 & Nong Phlup Agromet & 500301 & 1076.8 & Weibull & 0.655 & 0.647 & 5.983 \\
\hline 96 & Khlong Yai* & 501201 & 4635.1 & Gamma & 0.485 & 0.573 & 43.007 \\
\hline 97 & Chumphon* & 517201 & 1923.6 & Weibull & 0.545 & 0.692 & 8.920 \\
\hline 98 & Sawi Agromet & 517301 & 1931.4 & Weibull & 0.541 & 0.721 & 9.218 \\
\hline 99 & Ranong* & 532201 & 4114.7 & Gamma & 0.466 & 0.612 & 34.461 \\
\hline 100 & Surat Thani* & 551201 & 1639.8 & Weibull & 0.571 & 0.695 & 7.999 \\
\hline 101 & Phunphin Airport & 551202 & 1587.0 & Weibull & 0.573 & 0.699 & 7.813 \\
\hline 102 & Ko Samui* & 551203 & 2001.4 & Weibull & 0.570 & 0.644 & 8.866 \\
\hline 103 & Surat Thani Agromet & 551301 & 1951.9 & Weibull & 0.456 & 0.697 & 7.495 \\
\hline 104 & Phra Sang & 551401 & 1839.6 & Weibull & 0.418 & 0.723 & 6.920 \\
\hline 105 & Nakhon Si Thammarat* & 552201 & 2504.5 & Weibull & 0.534 & 0.659 & 10.549 \\
\hline 106 & Khanom* & 552202 & 2037.2 & Weibull & 0.377 & 0.650 & 6.212 \\
\hline 107 & $\begin{array}{l}\text { Nakhorn Sri Thammarat } \\
\text { Agromet }\end{array}$ & 552301 & 2361.4 & Weibull & 0.495 & 0.694 & 9.761 \\
\hline 108 & Chawang & 552401 & 2081.9 & Weibull & 0.367 & 0.723 & 7.168 \\
\hline 109 & Phatthalung Agromet & 560301 & 2087.8 & Weibull & 0.497 & 0.682 & 8.517 \\
\hline 110 & Takua Pa* & 561201 & 3304.4 & Weibull & 0.446 & 0.730 & 13.352 \\
\hline 111 & Phuket* & 564201 & 2261.9 & Weibull & 0.530 & 0.758 & 11.086 \\
\hline 112 & Phuket Airport* & 564202 & 2525.1 & Weibull & 0.500 & 0.721 & 11.124 \\
\hline 113 & Ko Lanta* & 566201 & 2202.4 & Weibull & 0.506 & 0.733 & 9.949 \\
\hline 114 & Krabi* & 566202 & 2267.4 & Weibull & 0.378 & 0.750 & 8.329 \\
\hline
\end{tabular}


Table 3. The fit parameter of best fit distribution in each rain gauge (continues).

\begin{tabular}{|c|c|c|c|c|c|c|c|}
\hline No & station & code & $\begin{array}{c}\text { Mean, } \\
\text { mm }\end{array}$ & Fit dist. & Inflated & shape & scale \\
\hline 115 & Trang Airport* & 567201 & 2166.6 & Weibull & 0.529 & 0.729 & 10.242 \\
\hline 116 & Kho Hong Agromet & 568301 & 2047.6 & Weibull & 0.555 & 0.678 & 9.467 \\
\hline 117 & Sa Dao & 568401 & 1735.0 & Weibull & 0.418 & 0.668 & 5.979 \\
\hline 118 & Songkhla* & 568501 & 2100.2 & Weibull & 0.574 & 0.649 & 9.529 \\
\hline 119 & Hat Yai Airport* & 568502 & 1753.7 & Weibull & 0.552 & 0.676 & 8.008 \\
\hline 120 & Satun* & 570201 & 2239.1 & Weibull & 0.479 & 0.712 & 9.368 \\
\hline 121 & Pattani Airport* & 580201 & 1868.0 & Weibull & 0.598 & 0.680 & 9.523 \\
\hline 122 & Yala Agromet & 581301 & 2181.8 & Weibull & 0.487 & 0.661 & 8.435 \\
\hline 123 & Narathiwat* & 583201 & 2518.6 & Weibull & 0.530 & 0.638 & 10.173 \\
\hline
\end{tabular}




\section{Appendix II: List of Figures}
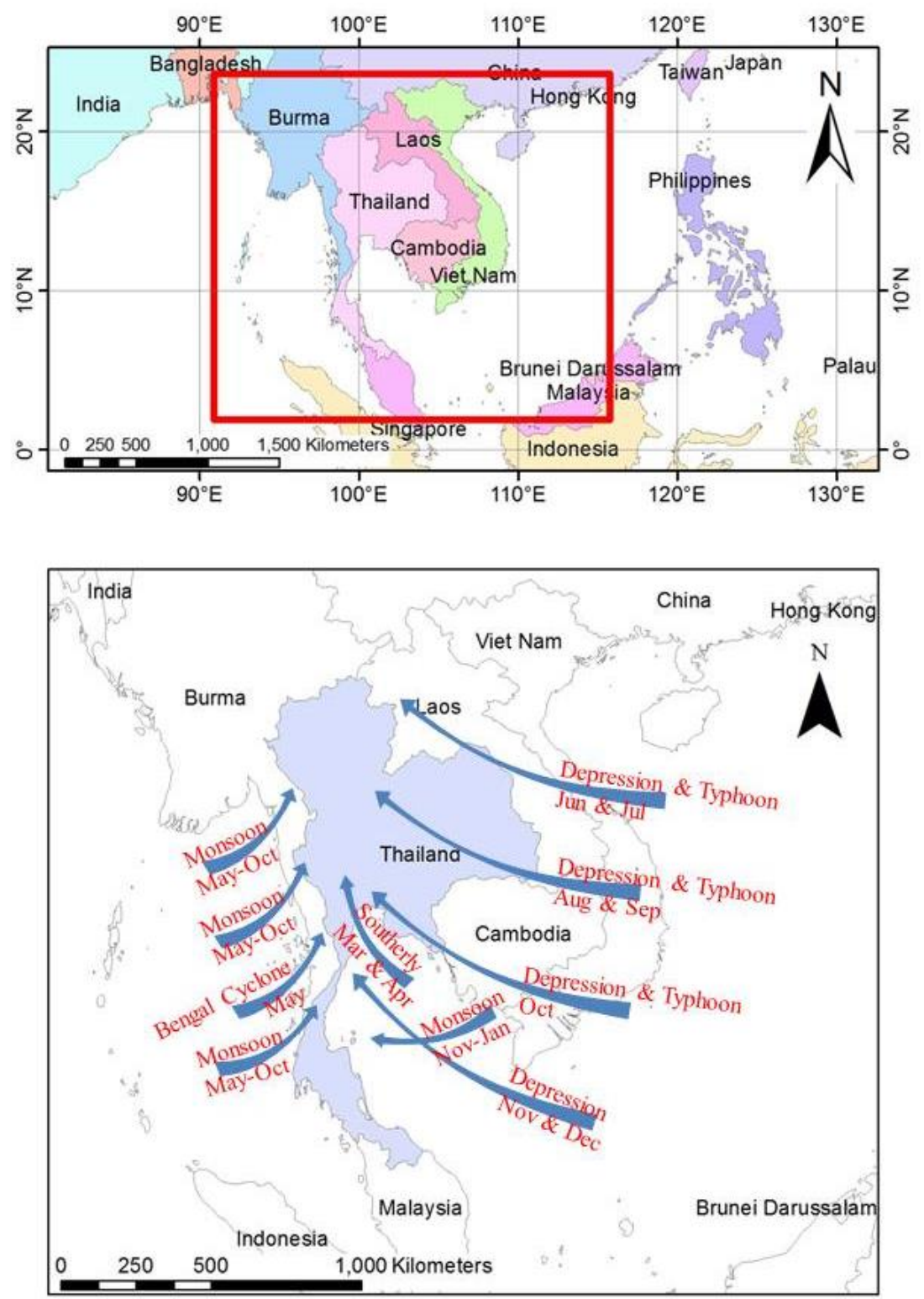

Fig. 1. Map of Southeast Asia, which shows the location and Wind system of Thailand. 


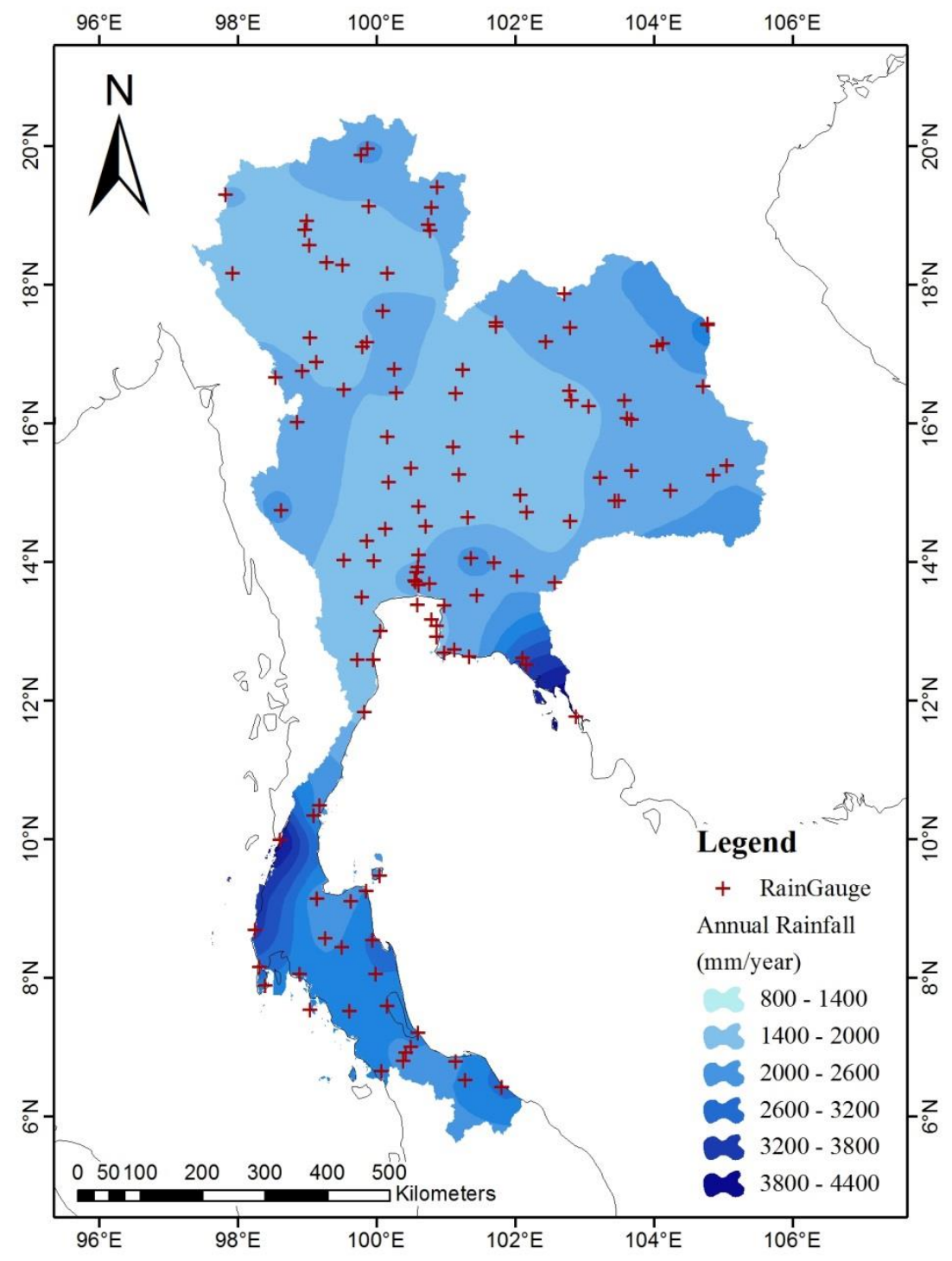

Fig. 2. Location of the 123 rain gauges and annual average rainfall in Thailand. 


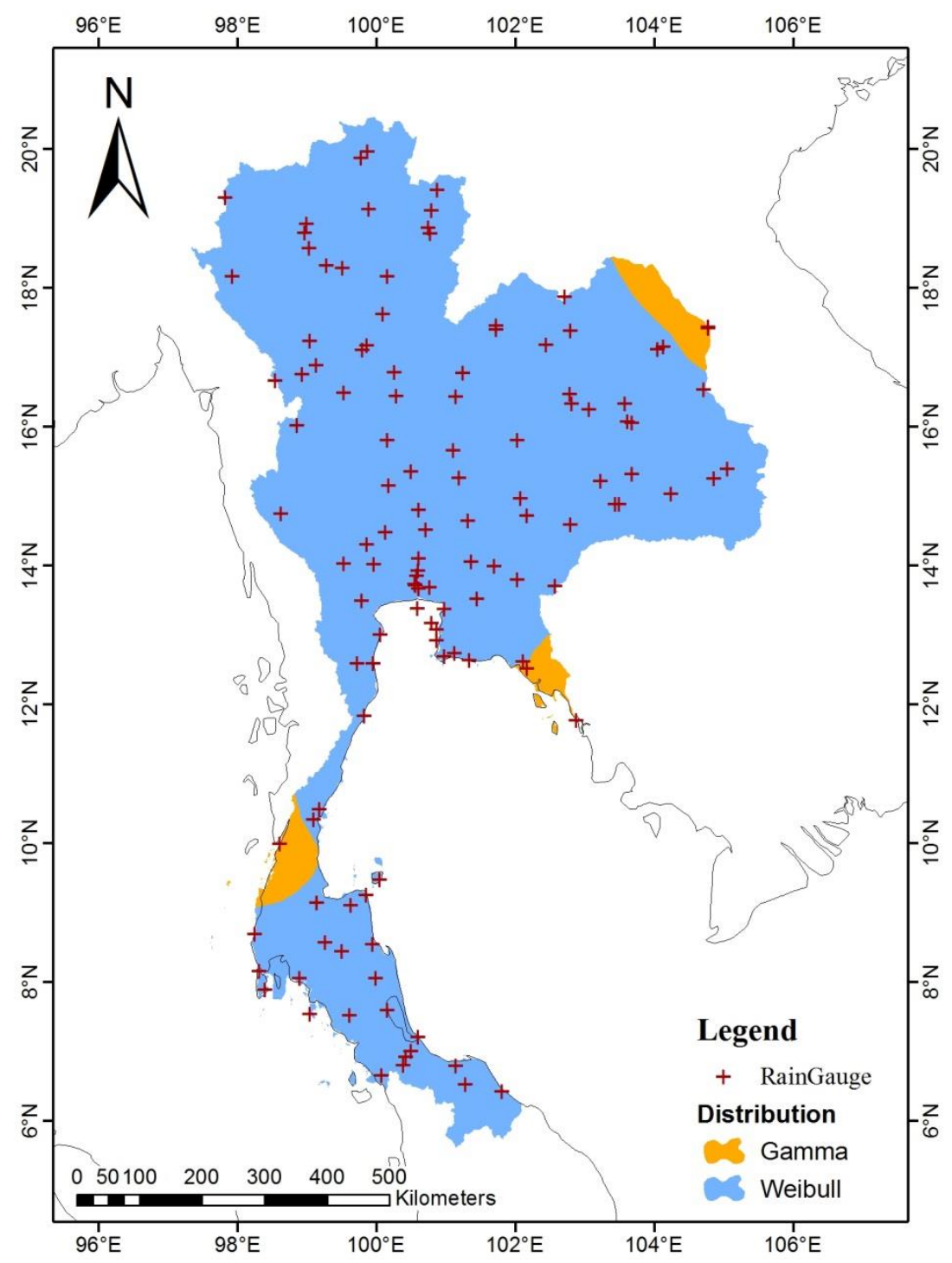

Fig. 3. The best-fit probability distribution of rain gauges on daily rainfall in Thailand. 